
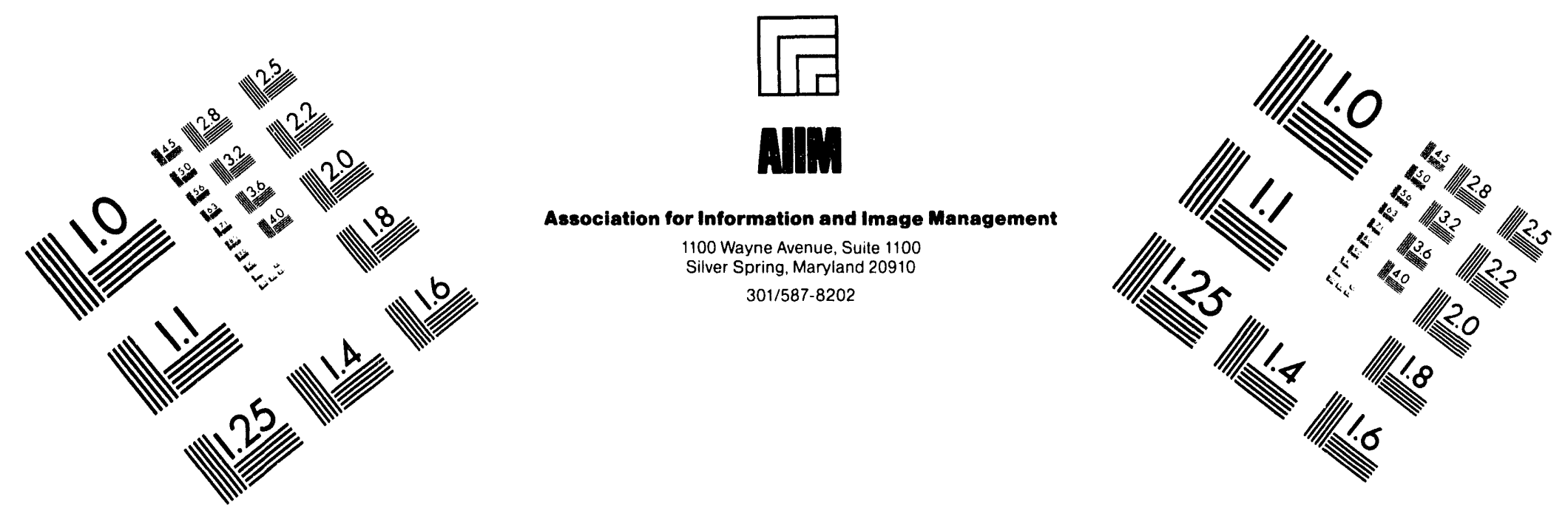

Centimeter

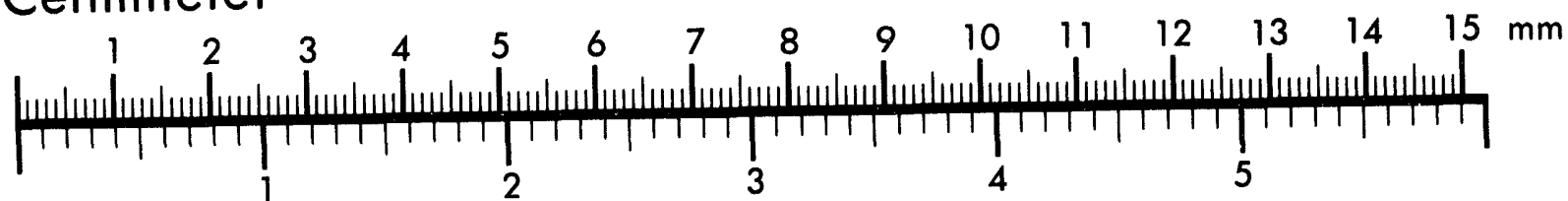
Inches
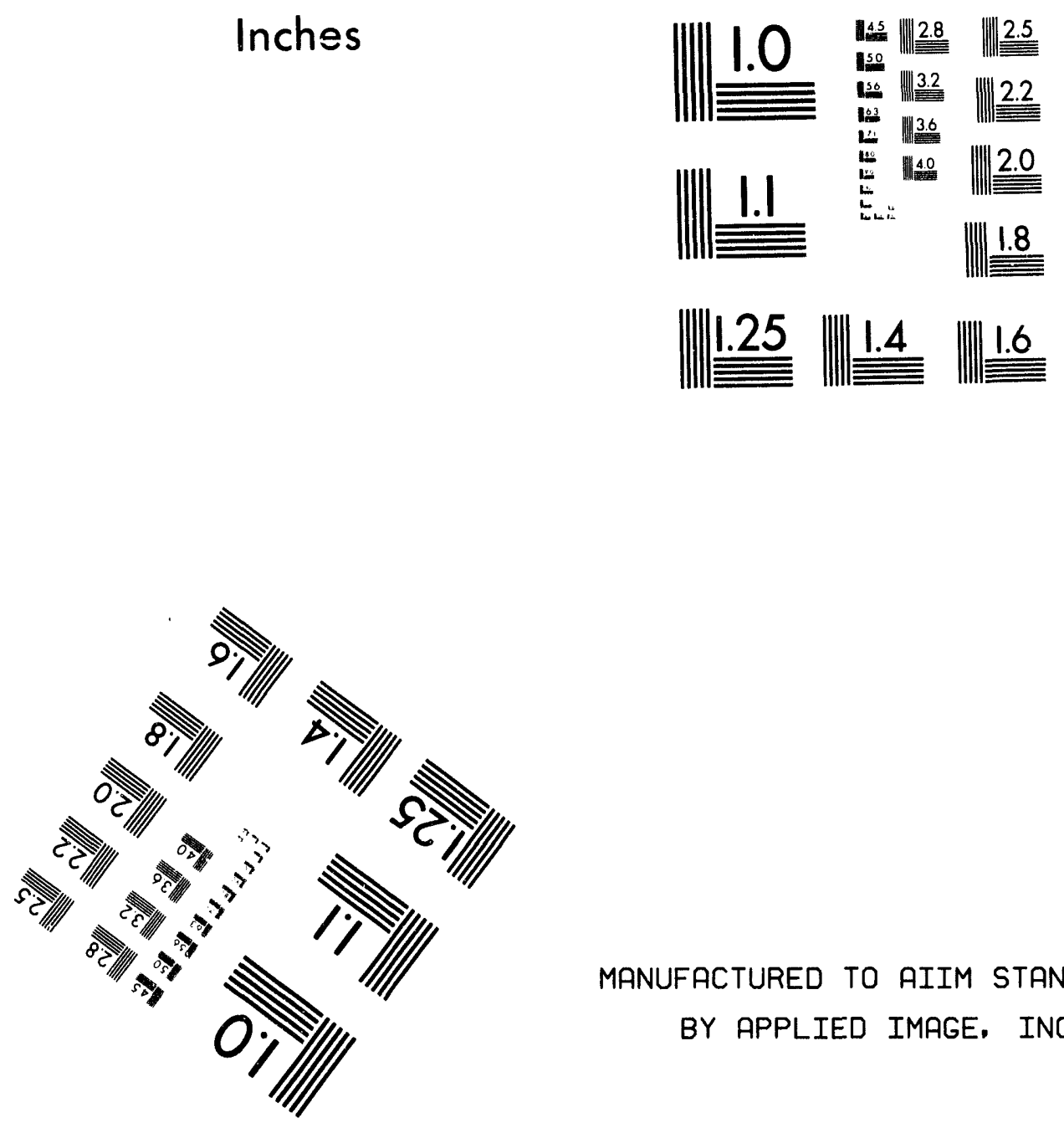

MANUFACTURED TO AIIM STANDARDS

BY APPLIED IMAGE, INC.

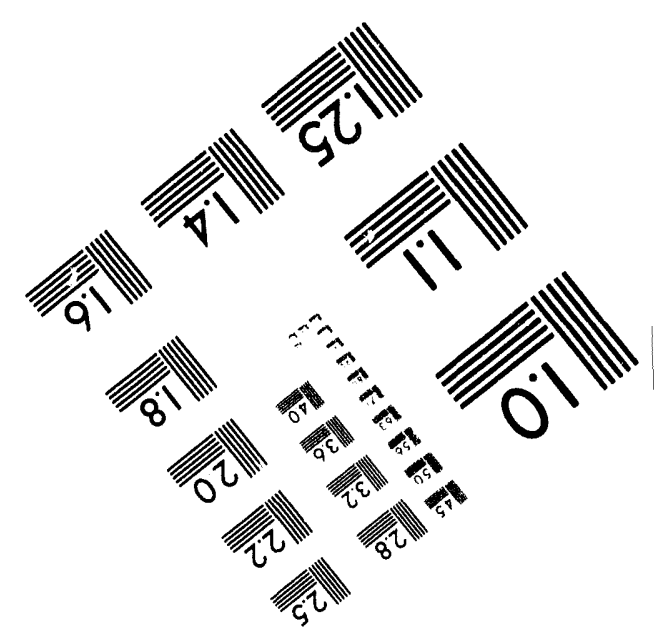



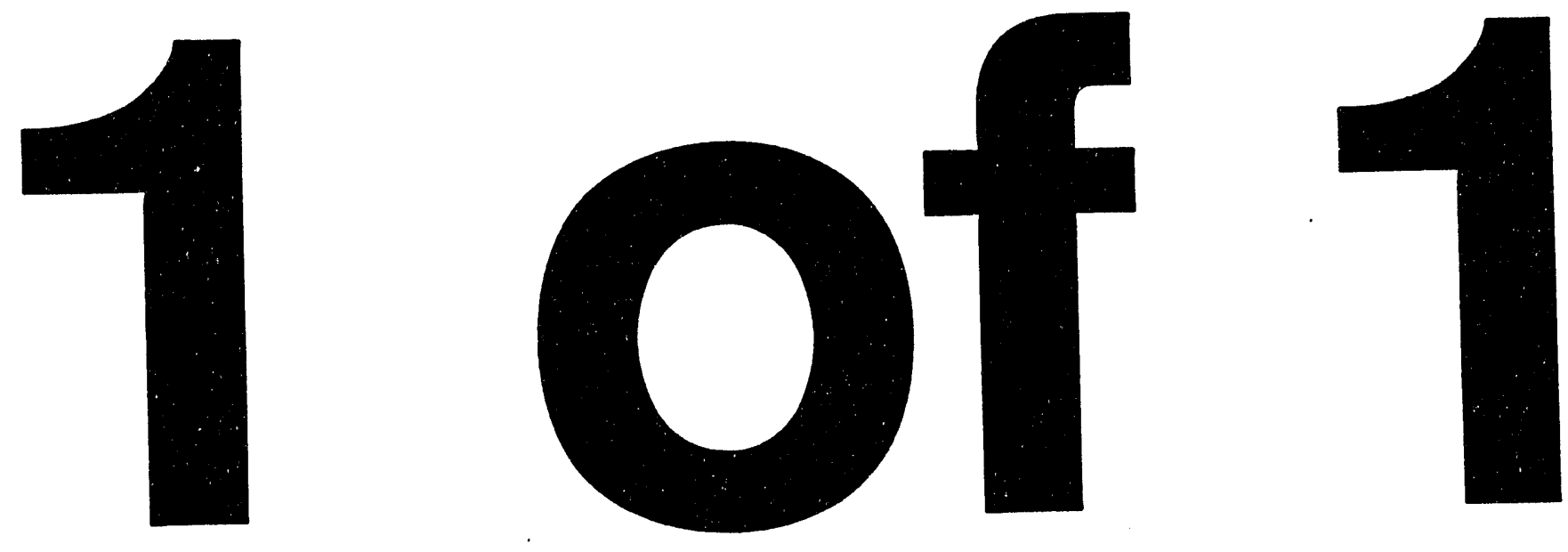


\title{
Investigation of Magnetic Reconnection during a Sawtooth Crash in a High Temperature Tokamak
}

\author{
by \\ M. Yamada, F. Levinton*, N. Pomphrey, R. Budney, \\ J. Macickam and Y. Nagayama** \\ Princeton Plasma Physics Laboratory, Princeton University \\ P.O.Box 451, Princeton, New Jersey 08543
}

\begin{abstract}
This paper reports on a recent laboratory investigation on magnetic reconnection in high temprature tokamak plasmas. The motional stark effect(MSE) diagnostic is employed to measure the pitch angle of magnetic field lines, and hence the q profile. An analytical expression that relates pitch angle to $q$ profile has been developed for a toroidal plasma with circular cross section. During the crash phase of sawtooth oscillations in the plasma discharges, the ECE (electron cyclotron emission) diagnostic measures a fast flattening of the 2-D electron temperature profile in a poloidal plane, an observation consistent with the Kadomtsev reconnection theory. On the other hand motional the MSE measurements indicate that central q values do not relax to unity after the crash, but increase only by $5-10 \%$, typically from 0.7 to 0.75 . The latter result is in contradiction with the models of Kadomtsev and/or Wesson. The present study addresses this puzzle by a simultaneous analysis of electron temperature and $\mathrm{q}$ profile evolutions. Based on a heuristic model for the magnetic reconnection during the sawtooth crash, the small change of q, i.e. partial reconnection, is attributed to the precipitous drop of pressure gradients which drive the instability and the reconnection process as well as flux conserving plasma dynamics.
\end{abstract}

*Fusion Physics and Technology Torrance, CA 90503

**University of Tsukuba, Japan 


\section{Introduction}

Magnetic reconnection, involves the breaking and topological rearrangement of magnetic field lines, and is an important relaxation process in plasma physics. ${ }^{2-7}$ Sawtooth oscillations ${ }^{8}$ in high temperature fusion plasmas are a manifestation of magnetic reconnection, and play an important role in determining confinement characteristics. ${ }^{9-11}$ Magnetic reconnection is also a key process in the description of evolution mechanisms for solar flares, ${ }^{3}$ the earth's magnetosphere ${ }^{4}$ and some low temperature laboratory experiments. ${ }^{5-7}$

A sawtooth oscillation is characterized by a periodic collapse or crash of the central plasma pressure..$^{8-11}$ Although there are several theoretical models for the sawtooth, Kadomtsev's model ${ }^{10}$ developed twenty years ago has attained the widest acceptance. According to this model an $m=n=1$ resistive internal mode is unstable for $q_{0}<1$ ( $m$ and $n$ are the poloidal and toroidal mode numbers and $q_{0}$ is the safety factor at the magnetic axis), and grows until a full magnetic reconnection process flattens the pressure and current profiles causing the central $q$ value to increase to unity.

Evolution of the central $q$ values have been measured by a number of groups for the past several years. ${ }^{12-17}$ There is agreement among all experiments that the relative change of the central $q$ during a sawtooth crash is small $(\Delta q / q<0.1)$. However, there is a major difference among reported final values of the central $q$ after the crash. Most recently, Wroblewski and Snider ${ }^{17}$ reported that central $q$ values on DIII-D ${ }^{1}$ rise to unity, claiming that their observation is evidence of Kadomtsev reconnection.

The primary subject of the present paper is an experimental study of magnetic reconnection in high temperature TFTR(Tokamak Fusion Test Reactor) ${ }^{1}$ plasmas (where the Magnetic Reynolds number exceeds $10^{7}$ ) by a set of non-perturbative diagnostics. During the crash phase of sawtooth oscillations, ECE (electron cyclotron emission) and Soft-Xray diagnostic systems ${ }^{18-20}$ observe that the temperature gradient inside the inversion radius diminishes to nearly zero after the crash. This observation is consistent with predictions of the Kadomtsev ${ }^{10}$ model. However, $q(R)$ profiles measured by motional Stark effect (MSE) diagnostics ${ }^{21}$ indicate that central $q$ values increase typically from 0.7 to 0.8 during the sawtooth crash phase and do not relax to unity even while the pressure gradient diminishes inside the $q=1$ region. This latter observation is an important contradiction with the theories of Kadomtsev ${ }^{10}$ and Wesson. ${ }^{11}$

We address this puzzle by a simultaneous analysis of electron temperature and $q$ profile evolution during sawtooth oscillations. Small changes of $q(R)$ are documented. Based on a heuristic model for magnetic reconnection during the sawtooth crash, the small change of $q$ (implying limited reconnection) is attributed to the combined effects of flux conserving plasma dynamics and to the precipitous drop of the pressure 
gradients which drive the instability and reconnection process.

\section{Electron Temperature Evolution in Sawtooth Crash}

The electron temperature profile on the midplane of the plasma is measured with a 20 channel grating polychrometer ${ }^{21,18,19}$ and with a $2 \mu \mathrm{sec}$ time step covering $R=2.1-3.4 \mathrm{~m}$ with a spatial channel separation of $6 \mathrm{~cm}$. A two-dimensional(2-D) electron temperature profile on a poloidal plane can be obtained by making use of the fast toroidal rotation of the plasma. The image reconstruction techniques using rotation have been described in a previous publication together with an analysis of the reconstruction errors. ${ }^{18-20}$ The present work extends this 2-D imaging technique to elucidate electron heat flow during sawtooth oscillation.

Profiles of electron temperature in a poloidal plane, $T_{e}(r, \theta)$, are conveniently represented as three-dimensional(3-D) plots with the vertical axis denoting electron temperature. Changes in temperature profile during a sawtooth cycle can be represented by the differences $\Delta T_{e}(r, \theta, t)=T_{e}(r, \theta, t)-T_{e}^{\text {base }}(r, \theta)$, where $T_{e}^{\text {base }}(r, \theta)$ is a base profile equal to the lowest value of $T_{e}(r, \theta, t)$ obtained at location $r, \theta$ at any time during a given sawtooth cycle. Overlaying color contours of $\Delta T_{e}$ on the 3-D $T_{e}(r, \theta)$ profiles allows one to visualize ${ }^{20}$ the inventory of electron thermal energy during a sawtooth period.

Fig. 1 shows the electron temperature profile evolution during a typical sawtooth crash, with overlayed color contours of $\Delta T_{e}$ depicting the transfer of electron thermal energy. The time interval between each of the four frames in the figure is $\approx 120 \mu \mathrm{sec}$, approximately equal to the plasma's toroidal rotation period at the time of the sawtooth crash. Fig. 1(a) shows an essentially axisymmetric pattern for $T_{e}$, giving no indication of the dramatic profile evolution that takes place between Fig. 1(b) and (c) during the sawtooth crash. Just before the collapse of the peak temperature, when the pressure reaches a threshold value, the temperature peak shifts radially within the inversion radius $r(q=1)$ and shrinks in size. Also within the inversion radius is seen a growing crescent-shaped flat temperature region ${ }^{22,23}$ corresponding to the development of a helical $m / n=1 / 1 \mathrm{kink}$ mode. The $T_{e}$ profile inside the inversion radius is nearly flat after the crash (see Fig. 1(d)). The electron density is observed to flatten on a similar $(\sim 200 \mu \mathrm{sec})$ time scale. CHERS(Charge Exchange Recombination Spectroscopy) diagnostics also observe a flattening of the ion temperature after the crash although the time resolution of this diagnostic is as long as $50 \mathrm{msec}$. The entire crash phase takes $150-800 \mu \mathrm{sec}$, while a sawtooth period is $100-200$ msec. The spatial $(<6 \mathrm{~cm})$ and time $(\sim 10 \mu \mathrm{sec})$ resolutions of this representation were discussed with a description of the image reconstruction techniques in previous publications. ${ }^{18-20}$ 
To describe the electron heat flow pattern semi-quantitatively we approximate a time derivative of the electron temperature profile on a poloidal plane as

$$
\delta T_{e}(r, \theta, t) / \delta t=\left[T_{e}(r, \theta, t+\tau)-T_{e}(r, \theta, t)\right] / \tau
$$

where, $\tau$ is the plasma's toroidal rotation period, typically $50 \mu \mathrm{sec}$ and usually much shorter than the crash phase period. Fig. 2 shows a typical heat flow pattern by overlaying a graded color representation for $\delta T_{e}(r, \theta, t) / \delta t$ on $T_{e}(r, \theta)$ contour lines for a sawtoothing discharge. The rotation period in this case is $120 \mu \mathrm{sec}$. Blue shading represents a heat loss of approximately $1 \times 10^{4} \mathrm{KeV} / \mathrm{sec}$, and red a heat gain of $1 \times 10^{4} \mathrm{KeV} / \mathrm{sec}$. Frames a, b, c, and d of Fig. 2 refer to the same times as the corresponding frames in Fig. 1. During the period of development of the crescent-shaped flat temperature region, heat flow is essentially confined within the $q=1$ radius. Fig. 2(b) shows heat flow around the circular high-temperature peak toward the intersection of the hot region with the $q=1$ surface (X-region). Fig. 2(c),(d) shows transfer of heat through the X-region to the outside of the $q=1$ radius. Later, we present a heuristic model in which partial magnetic reconnection causes anomolously fast heat flow through the X-region.

A more accurate presentation with a better time resolution of heat flow is shown in Fig. 3. Here, color contours of $\delta T_{e}(r, \theta, t) / \delta t$, together with $T_{e}(r, \theta)$ contours (solid lines), are shown for a discharge with a shorter rotation period of $\tau=54 \mu \mathrm{sec}$. The four frames that make up Fig. 3 correspond to the time values (a) $t=206 \mu \mathrm{sec}$, (b) $t=$ $314 \mu \mathrm{sec},(\mathrm{c}) t=368 \mu \mathrm{sec}$, and $(\mathrm{d}) t=422 \mu \mathrm{sec}$. Here, $t=0$ refers to the time at which an $m / n=1 / 1$ precursor oscillation was first detected. Again, blue shading represents a heat loss of approximately $1 \times 10^{4} \mathrm{Kev} / \mathrm{sec}$, and red a heat gain of $1 \times 10^{4} \mathrm{KeV} / \mathrm{sec}$. During the period of development of the $1 / 1$ mode, heat flow is essentially confined within the $q=1$ radius. Fig. 3(a) and Fig. 3(b) show heat flow around the base of the circular high-temperature peak toward the intersection of the hot region with the $q=1$ surface (X-region). Fig. 3(c),(d) show transfer of heat through the Xregion to $r>r(q=1)$, then away from the $\mathrm{X}$-region. Fast 1-D radial electron heat transport outside of the $q=1$ radius has been studied during and after the crash as a propagating heat pulse by Fredrickson et.al.. ${ }^{24}$

\section{Measurement of q-profile by Motional Stark Effect}

We employ the motional Stark effect diagnostic to obtain the profile of magnetic pitch angle, and hence the $q$ profile, using polarimetry measurements of the Doppler shifted $D_{\alpha}$ emission from a neutral deuterium-beam (NBI) heating line. ${ }^{25,26,21}$ As a neutral beam penetrates through a plasma, collisions with background plasma ions 
and electrons excite beam atoms, leading to $D_{\alpha}$ emission. By measuring the polarization of the " $\sigma$ component" of the beam fluorescence, the pitch angle of the magnetic field lines can be determined wherever the beam penetrates the plasma. An important advantage of this technique is that the noninvasive and nonperturbative measurement of the field-line pitch is localized to the geometric intersection of the field of view with the neutral beamlines, which leads to good spatial resolution of $\delta r=3 \sim 5 \mathrm{~cm}$. The time resolution is as short as $5 \mathrm{msec}$ but typically $10 \mathrm{msec}$.

If the plasma is considered to have good flux surfaces, the measured field line pitch can be translated into a radial profile of the safety factor, $q(R)$, based on tokamak equilibrium calculations. ECE and interferometer diagnostic measurements show that $T_{e}$ and $n_{e}$ profiles are axisymmetric throughout the sawtooth period except during the crash phase, suggesting that magnetic flux surfaces are also axisymmetric. The next section describes how the $q(R)$ profile may be derived from the measured pitch angle data.

\section{IV. q-profile determination from pitch angle data}

The relationship of magnetic field pitch angle to the $q(R)$ profile depends on the configuration (aspect ratio, $a / R$, elongation, triangularity) and on plasma parameters such as poloidal beta and internal plasma inductance. ${ }^{27}$ For TFTR plasmas at modest beta, it is a good approximation to assume that magnetic flux surfaces form a nested set of shifted circles on a poloidal plane, i.e.,

$$
\begin{aligned}
X & =R-\Delta(r)-r \cos \theta, \\
Z & =r \sin \theta .
\end{aligned}
$$

Here $R$ is the magnetic axis location, $\Delta(r)$ is the Shafranov Shift (distance between magnetic axis and center of flux surfaces), and $r$ is the minor radius of a flux surface.

Consider the conventional definition of magnetic field for an axisymmetric toroidal system:

$$
\mathbf{B}=B_{0} R_{0}[\nabla \phi \times \nabla \chi(r)+g(r) \nabla \phi]
$$

where, $\chi$ is the poloidal flux within a flux surface labelled by coordinate $r$, and $g$ is the toroidal flux function. The shifted circle approximation allows a straightforward derivation of a closed-form expression for the safety factor $q(r)$. From the definition

$$
q=\frac{1}{2 \pi} \int_{0}^{2 \pi} \frac{\mathbf{B} \cdot \nabla \phi}{\mathbf{B} \cdot \nabla \theta} d \theta
$$


we eliminate $\chi^{\prime} / g$ in favor of the midplane magnetic pitch angle, $\gamma$, using

$$
\begin{aligned}
\tan \gamma_{ \pm} & \equiv B_{p} / B_{t}\left(X_{ \pm}\right) \\
& = \pm \frac{\chi^{\prime}}{g\left(1 \pm \Delta^{\prime}\right)}
\end{aligned}
$$

Here prime denotes derivative with respect to $r$, pitch angle is regarded as a function of midplane radius $X$, and $+/$ - refers to outboard/inboard with respect to the magnetic axis. The required $\theta$ integration yields

$$
q(r)= \pm \frac{r}{R \tan \gamma_{ \pm}\left(1 \pm \Delta^{\prime}\right)}\left[-\frac{R \Delta^{\prime}}{r}+\left(1+(R-\Delta) \frac{\Delta^{\prime}}{r}\right) / \sqrt{\left(1-\frac{\Delta}{R}\right)^{2}-\left(\frac{r}{R}\right)^{2}}\right]
$$

where

$$
\tan \gamma_{+}\left(1+\Delta^{\prime}\right)=-\tan \gamma_{-}\left(1-\Delta^{\prime}\right)
$$

is a constraint which follows from Eq. (7) and the fact that $\chi^{\prime}$ and $g$ are constant on a given flux surface.

MSE data provides pitch angle information for a range of midplane $X$ values. Within the range, the pitch angle data may be fit to a continuous function: $\tan \gamma_{ \pm} \equiv$ $T_{ \pm} \Rightarrow T(X)$. If the range spans the magnetic axis, the axis location $X=R$ is determined from the zero of $T(X)$. Consider now two possibilities:

(P1) The range of $X$ for which pitch angle data is obtained spans a region roughly centered on the magnetic axis. In this case we can rewrite Eq. (9) as

$$
\Delta^{\prime}=\frac{T_{+}+T_{-}}{T_{+}-T_{-}}
$$

showing that $\Delta^{\prime}(r)$ and hence $q(r)$ can be calculated from knowledge of pitch angle data on both sides of the magnetic axis. We note that Eq. (10) is nonlinear in $\Delta$, since the arguments of $T_{ \pm}$are $X_{ \pm}=r \mp \Delta(r)$. An effective solution procedure is to expand $\Delta(r)$ in a linear combination of radial basis functions and to solve Eq. (10) by a combination of iteration and least squares fitting.

Now consider the second possibility, which is relevant for the MSE set-up on TFTR:

(P2) Pitch angle data is obtained in a range of $X$ values which includes the magnetic axis, but which lies predominantly between the magnetic axis and the outboard plasma edge. $R$ is again determined by the zero of $T(X)$, however Eq. (9) can no 
longer be used to determined $\Delta^{\prime}$ since the right side of the equation is unknown for most of the window. The equation relating the data to the Shafranov Shift is now Eq. (7), i.e.,

$$
\tan \gamma_{+}=\frac{\chi^{\prime}}{g\left(1+\Delta^{\prime}\right)}
$$

which is a single equation in (effectively) two unknowns; $\Delta^{\prime}$ and the ratio $\chi^{\prime} / g$. An additional assumption is needed to determine the plasma geometry, and hence $q(r)$, from the pitch angle data.

To proceed, we assume that $\Delta^{\prime}$ is determined by an inverse aspect ratio expansion of the plasma equilibrium equations. To leading order in the aspect ratio and assuming the standard low beta tokamak ordering, ${ }^{27}$ we have $g=1$ and $\Delta^{\prime}$ related to $\chi^{\prime}$ through

$$
\begin{aligned}
\Delta^{\prime}(r) & =\frac{1}{R r \chi^{\prime 2}} \int^{r}\left(\chi^{\prime 2}-2 r p^{\prime} / B_{0}^{2}\right) r d r \\
& =\frac{r}{R}\left(\tilde{\beta}_{\theta}+\tilde{\ell}_{i} / 2\right)
\end{aligned}
$$

where

$$
\begin{aligned}
\tilde{\beta}_{\theta}(r) & =-\frac{1}{r^{2} \chi^{\prime 2}} \int^{r} \frac{2 r^{2} p^{\prime}}{B_{0}^{2}} d r \\
\tilde{\ell}_{i} / 2(r) & =\frac{1}{r^{2} \chi^{\prime 2}} \int^{r} \chi^{\prime 2} r d r
\end{aligned}
$$

are poloidal beta and internal inductance profile functions. For the simplest approximation, assume a constant current density and a parabolic pressure profile in the plasma. Then $\chi^{\prime}$ and $p^{\prime}$ are linear in $r$ and

$$
\Delta(r)=\frac{r^{2}}{2 R}\left(\beta_{\theta}+\ell_{i} / 2\right)
$$

where $\beta_{\theta}$ and $\ell_{i}$ are constant, and $\ell_{i}=0.5$. For more general profiles, eg., $J(r)=$ $J_{0}\left(1-r^{2} / a^{2}\right)^{\alpha_{J}}$ and $p(r)=p_{0}\left(1-r^{2} / a^{2}\right)^{\alpha_{p}}$ we can write

$$
\Delta(r)=f\left(r ; \alpha_{p}, \alpha_{J}\right)\left(\beta_{\theta}+\ell_{i} / 2\right) .
$$

However, Eq. (16) has been shown to be accurate to within $5 \%$ for $\rho \beta_{p} / R_{\text {mag }}<0.5$ using the PEST ${ }^{28}$ equilibrium code, and we use Eq. (8) and Eq. (16) for the present analysis. The combination $\beta_{\theta}+\ell_{i} / 2$ is determined by magnetic measurements. 


\section{Measurement of $q$ profiles}

The $q$ profiles before and after the sawtooth crash have been examined for typical neutral beam heated ( $P_{b}=8-11 \mathrm{MW}$ ) TFTR plasmas with toroidal current of $1.8 M A$. Fig. 4 presents typical $q(R)$ profiles before and after a sawtooth crash. The statistical error in calculated $q$ values is estimated to be less than $2.5 \%$, although the systematic error is evaluated to be about $5 \%$ for $q(R)$ data based on a comparative analysis with the ECE inversion radii and by moving the magnetic axis radially for cross-calibration. ${ }^{21}$ About two dozen similar discharges have been investigated and the central $q$ values typically change between 0.70 and 0.80 during a sawtooth with a relative error of $2 \%$. The central $q$ values typically increase by $10 \%$ during the crash. This observation is in agreement with earlier results from TEXTOR and JET. ${ }^{1}$

Fig. 5(a) presents time evolution of central $q$ values from MSE and the central electron temperature from the ECE signals in a typical sawtooth discharge. Correlated with the sawtooth collapse is a small rise of $\sim 0.08$ for $q_{0}$. In this example, as well as most TFTR discharges, $q_{0}$ is below one when sawteeth are present, and I $u$ mains below unity throughout the sawtooth cycle. In order to reduce the statistical uncertainty and improve the time resolution, which is $30 \mathrm{msec}$ for the data shown here, we can synchronousiy or co-average the data over several sawteeth as shown in Fig. 5(b). Because only field-line breaking and re-arrangement can make a $q(R)$ change on such a short time scale (《 magnetic diffusion time), the observations verify a magnetic field-line reconnection, albeit small.

\section{Proposed Physical Model for Sawtooth Crash}

The observations raise the question as to why the magnetic field lines inside the $q=1$ region do not form a flat $q \sim 1$ inner region after the crash as suggested by Kadomtsev, ${ }^{10}$ while the temperature gradient diminishes to zero as predicted by him for full reconnection. The clues to answering this question lie in the heat flow pattern shown in Fig. 2 and Fig. 3 during the crash phase.

The plasma may be viewed as concentric toroidal regions separated by the $q=1$ surface. Plasma heating leads to an increase in pressure gradient, $p^{\prime}$, and a decrease in $q_{0}$. When $p^{\prime}$ exceeds a critical value depending on the local shear, an $m / n=1 / 1$ ideal kink mode is triggered in the inner (core) region. ${ }^{23}$ Flux surfaces are displaced rapidly outwards on an Alfven timescale (cf $T_{e}$ profile in Fig. 1(b) and $T_{e}$ contours in Fig. 2(b) and 3(a,b)). The plasma region outside of $q=1$ plays the role of a stabilizing conducting shell which suppresses the flux displacements by inducing image currents near the interface of the core and shell. A current sheet and X-point are formed. Unlike the flux, the pressure is not so constrained by the outer region during the 
kink evolution. In the last stage of development of the kink mode, the pressure and flux contours inside $q=1$ do not coincide. The mismatch during this period is an important distinction from Kadomtsev's model which always assumes the pressure and flux surfaces coincide. We speculate that the observed enhanced perpendicular heat conduction is caused by a connection of different pressure contours by field lines of the mismatched flux surfaces. The local p:essure gradient is strongest at the X-point (cf Fig. 2(b), 3(b) showing the steepest temperature gradient in the $\mathrm{X}$-point region inside $q=1$ ). The physics of finite resistivity in the current sheet now enters the problem, and reconnection takes place according to the standard reconnection theories. ${ }^{3,4} \mathrm{~A}$ fast magnetic reconnection is induced at the $\mathrm{X}$-point and a partial reconnection of magnetic field lines occurs connecting the crescent shaped inner region (see Fig. $1(\mathrm{~b}, \mathrm{c})$ ) to the region outside of the inversion radius. ${ }^{22,23} \mathrm{~A}$ rapid efflux of thermal energy occurs through the $\mathrm{X}$-point region due to large parallel transport along newly connected field lines (cf Fig. 2(c,d) and 3(c,d)). Parallel plasma transport is so fast that the pressure equalization happens in i ime much shorter than the theoretical magnetic reconnection time., ${ }^{3,10}$ The time scale for this fast electron heat conduction process to equalize $T_{e}$ on a poloidal contour is estimated to be the electron heat conduction time along field lines, $\pi R / v_{e}$ times $q / \Delta q$, where $\Delta q$ denotes the width of $q$ values in the reconnection region. This value, $\pi R / v_{e} q / \Delta q$ is about $10-20 \mu \mathrm{sec}$ for $q / \Delta q \sim 10$ in the present plasma. The precipitous drop of the pressure gradient removes the free energy to drive the $m / n=1 / 1$ instability, inhibiting further progress of the mode and thus full reconnection.

The drop in pressure gradient should induce a decrease in the central current density (increase in $q_{0}$ ) because of force balance. Such a change would lead to a decrease in the internal plasma inductance, $\ell_{i}$. However, in a highly conducting plasma, flux conservation will inhibit a radical change of $\ell_{i}$, and prevent complete flattening of the current and $q$ profile inside $q=1$. Consequently, the amount of the $q(R)$ change can be small, and $q_{0}$ does not have to rise to unity for $\nabla p \sim 0$. (Note that there are multiple solutions for $j(R)$ which satisfy $\mathbf{j x B}=\mathbf{0}$ for $q<1$, if $\mathbf{j} \cdot \mathbf{B} / B^{2}$ is not constant ${ }^{2}$ with respect to $R$ ).

\section{Discussion and Conclusions}

A TRANSP analysis of the sawtoothing discharges provides a useful check on the amount of partial reconnection. The TRANSP ${ }^{29}$ uses measured plasma profiles and the measured plasma boundary. Typically, measured profiles of the electron temperature (from ECE, Fig. 6(b)) and the temperature and toroidal rotation velocity of the trace carbon impurity (from neutral-beam induced charge-exchange recombination spectroscopy) are used as initial inputs. Profiles for the hydrogenic ion temperature 
$T_{i}$ are computed from the impurity ion temperature. Monte-Carlo techniques are used to compute the time evolution of the beam ions. The beam ions are assumed to slow down classically. The assumptions of classical slowing down and loss have been checked in the case of beam ions and DD fusion products. Approximately six seconds of the discharge evolution is modeled, starting about $0.5 \mathrm{sec}$ after initiation and continuing through the neutral beam injection. For these experiments the neutral beam injection starts at $4 \mathrm{sec}$ and extends to $6 \mathrm{sec}$.

Fig. 6 presents a set of plasma parameter evolutions $\left(n_{e}, T_{e}\right)$ associated with sawtooth oscillations on which the TRANSP modeling are made, together with measured $q_{0}$ (by MSE), and $q_{\psi}(0)$ evolution deduced from the TRANSP calculation. The TRANSP plasma analysis code employs a phenomenological sawtooth model based on the helical flux mixing model. ${ }^{10}$ which is invoked at the observed sawtooth crash times if $q_{\psi}(0)<1$. The field lines are assumed to either not be mixed or to be only partly mixed by controling current density profile during the sawtooth crash and the results are compared with those from a case of the $100 \%$ field-line mixing in the standard Kadomtsev model. ${ }^{10}$ The TRANSP calculation can check whether the observed plasma profile evolutions are consistent with these current mixing models. Full field-line mixing predicts a $q_{\psi}(0)$ evolution between 0.9 and 1.0 and never reproduces the observed $q_{0}$ evolution to $0.70-0.85$ during the crashes. On the other hand, $0 \%$ current-mixing (no reconnection) produces much lower $q_{\psi}(0)$ values than oberved, without any sawteeth. As shown in Fig. 6(d), a simulation based on a partial mixing of field lines (20-30\%) leads to the best agreement with the experimental observations.

Evolution of central $q$ values has been measured by several groups in the past few years. ${ }^{12,13,17}$ There is agreement among all experiments that the relative change of central $q$ during $a$ sawtooth crash is small $(\Delta q / q \leq 0.1)$. However, there is a major difference among the experiments on the final values of the central $q$ after the crash. Wroblewski and Snider ${ }^{17}$ recently reported that the central $q$ values rise to 1 concluding that the observation is evidence of the Kadomtsev reconnection. Although the cause of this apparent disagreement with the present study is yet to be determined, it could be attributed to, 1) difficulties in $q(R)$ measurements and their analysis as noted by Wroblewski and Snyder, ${ }^{17}$ and/or 2) DIII-D generates non circular plasmas ${ }^{17}$ with different MHD properties from circular TFTR plasmas. We also note that most of the results that reported $\Delta q<0.1$ during sawtooth crash can be explained by our proposed model.

In summary, magnetic reconnection consistent with partial mixing of field-lines during a sawtooth crash, and small changes of central $q$ have been documented. The motional Stark effect(MSE) diagnostic has been employed to measure the pitch angle profile of magnetic field lines, and hence the $q$ profile. An analytical relationship between the pitch angle of field lines and $q$ profile has been developed for a toroidal 
plasma with circular cross section. It has been shown that central $q$ values stay substantially below 1 , despite $T_{e}$ contour evolution from ECE diagnostics which show full Kadomtsev-like 2-D reconnection patterns. A simultaneous analysis of poloidal $T_{e}(r, \theta)$ and $q(R)$ profile evolutions has led us to propose a heuristic model consistent in most of its features with that of Baty et $\mathrm{al}^{23}$ which was based on a non-linear 3-D MHD numerical simulation. In our model an $m / n=1 / 1$ ideal kink mode develops inside of the $q=1$ radius and induces a partial rearrangement of field lines, i.e., partial reconnection, through the X-point region where a circular hot spot touches the $q=1$ surface. A fast parallel transport along newly connected field lines can cause a rapid efflux of internal energy through the $\mathrm{X}$-point region and therefore a fast crash of the central plasma pressure. The small change of $q$ values associated with partial reconnection of field-lines is attributed to the precipitous drop of pressure gradients which drive the instability and the reconnection process, as well as a flux conservation principle.

\section{Acknowledgements}

Many valuable discussions with Drs. K. McGuire, W. Park, W. Stodiek, and L. Zakharov were highly appreciated. We also acknowledge skilled assistance by W. Davis and J. Stori. This work was supported by US. Department of Energy Contract No.DE-AC02-76-CHO3073. 


\section{Figures}

FIG. 1. $T_{e}(r, \theta)$ profiles in 3-D during the crash period of sawtooth. Heat transfer $\Delta T_{e}$ is superposed with coded color contours. The time interval between each figure is $\sim 120 \mu$ sec.

FIG. 2. Heat flow (in color) superimposed on $T_{e}(r, \theta)$ contours (solid lines) for times corresponding to Fig.1(a-d). Blue represents a heat loss of about $1 \times 10^{4} \mathrm{KeV} / \mathrm{sec}$ and red a gain of $1 \times 10^{4} \mathrm{KeV} / \mathrm{sec}$. The rotation period is $120 \mu \mathrm{sec}$. The dashed line represents the inversion radius which is close to the $q=1$ surface.

FIG. 3. Heat flow contours (in color) superposed on $T_{e}(r, \theta)$ contours (solid lines) for $t=216 \mu \sec (\mathrm{a}), 314 \mu \mathrm{sec}(\mathrm{b}), 368 \mu \mathrm{sec}(\mathrm{c})$ and $422 \mu \mathrm{sec}(\mathrm{d})$. Blue represents a heat loss of about $1 \times 10^{4} \mathrm{KeV} / \mathrm{sec}$ and red a gain of $1 \times 10^{4} \mathrm{KeV} / \mathrm{sec}$. The rotation period $\tau$ is $54 \mu \mathrm{sec}$. The dashed lines depict the inversion radius which is clcie to the $q=1$ radius measured by MSE.

FIG. 4. $q(R)$ profiles derived from MSE before and after a sawtooth crash. The magnetic axis is $276 \pm 3 \mathrm{~cm}$, both from ECE diagnostics and TRANSP analysis. The inversion radius of the ECE is about $301 \mathrm{~cm}$, which agrees with the $q=1$ radius from MSE, within the spatial resolution of the diagnostics.

FIG. 5. (a) Time evolution of central safety factor $q_{0}$ for a typical NBI heated L mode plasma together with the ECE based $T_{e}$ signal.

(b) Synchronously co-averaged data for one sawtooth period from 9 consecutive sawteeth . The averaging time perod is $5 \mathrm{msec}$ for each point. The crash occurs at $t=0$.

FIG. 6. Time evolution of measured central plasma parameters: (a) $n_{e}(0)$ from microwave interferometer; (b) $T_{e}(0)$ from ECE; (c) $q(0)$ from $\mathrm{MSE}$; (d) $q(0)$ from TRANSP calculation. A partial reconnection model with a current mixing rate of $20 \sim 30 \%$ agrees well with the measurement. 


\section{References}

${ }^{1}$ World Survey of Activities in Controlled Fusion Research (Nuclear Fusion special supplement 1991], (international Atomic Energy Agency, Vienna, 1991).

${ }^{2}$ J. B. Taylor, Rev. Mod. Phys., 28, 243 (1986).

${ }^{3}$ E.N. Parker, "Cosmical Magnetic Fields"(Oxford:Claredon Press, 1979).

${ }^{4}$ V.M. Vasyliunas, Rev. Geophys. Space. Phys., 13, 303 (1975).

${ }^{5}$ R. L. Stenzel and W. Gekelman, J. Geophys. Res., 86, 649 (1981).

${ }^{6}$ W. Gekelman and H. Pfister, Phys. Fluids, 31, 2017 (1988).

${ }^{7}$ M. Yamada, Y. Ono, A. Hayakawa, M. Katsurai, and F.w. Perkins, Phys. Rev. T,ett., 65, 721 (1990). Y. Ono, A. Morita, M. Katsurai and M. Yamada Phys. Fluids 5, 3691 (1993)

${ }^{8}$ S. von Goeler, W.Stodiek, and N.R. Sauthoff, Phys.Rev.Letts., 33,1201(1974).

${ }^{9} \mathrm{~J}$. A. Wesson, Tokamaks (Clarendon, Oxford, 1987), pp. 176-183.

${ }^{10}$ B. B. Kadomtsev, Sov., J. Plasma Phys., 1 , 389 (1975).

${ }^{11}$ J. A. Wesson, Plasma Phys. Contr. Fusion, 28, 243 (1986).

${ }^{12}$ H. Soltwisch, Rev. Sci. Instrum., 59, 1599 (1988).

${ }^{13}$ W.P. West, D.M. Thomas, J.S. DeGrassie, and S.M. Zhang, Phys. Rev. Lett., 58, 2758 (1987).

${ }^{14} \mathrm{H}$. Weisen, G. Borg, B. Joye, A.J. Knight, and J.B. Lister, Phys. Rev. Lett., 62, 434 (1989).

${ }^{15}$ R.C. Wolf, Nucl. Fusion 33, 663 (1993).

${ }^{16}$ T.H.Osborne, R.N. Dexter, and S.C. Prager, Phys. Rev. Lett., 49, 734 (1982).

${ }^{17}$ D. Wroblewski and R. Snider, Phys. Rev. Lett., 71, 859 (1993).

${ }^{18}$ Y. Nagayama, R. Buchse, A. Cavallo, E.D. Fredrickson,A.c. Janos, K.M. McGuire, G.Kuo Petravic, C. Sule and G. Taylor, Rev. Sci. Instrum., 61, 3265 (1990). 
${ }^{19}$ Y. Nagayama, K.M. McGuire,M. Bitter, A. Cavallo, E.D. Fredrickson, K.W. Hill, H. Hsuan, A. Janos, W. Park, G. Taylor, and M. Yamada, Phys. Rev. Letts., 67, 3527 (1991).

${ }^{20}$ M. Yamada, Y. Nagayama, W. Davis, E. Fredrickson, A. Janos, and F. Levinton, Rev. Sci. Instrum., 63, 4623, (1992).

${ }^{21}$ F. M. Levinton, S.H. Batha, M. Yamada, and M.C. Zarnstorff, Phys. Fluids, B5, 2554 (1993).

${ }^{22}$ A.J. Lichtenberg, Nucl. Fusion 24, 1277 (1984).

${ }^{23}$ H. Baty, J.F. Luciani, M.N. Bussac, Phys. Fluids B5, 1213, (1993).

${ }^{24}$ E. Fredrickson, Phys. Rev. Lett., 65, 2869 (1990).

${ }^{25}$ F.M. Levinton, Rev. Sci. Instrum., 63, 5157, (1992).

${ }^{26}$ F.M. Levinton, R.J. Fonck, G.M. Gammel,R. Kaita, H.W. Kugel, E.T.Powell, D.W. Roberts, Phys. Rev. Letts., 63, 2060 (1989).

${ }^{27}$ J. M. Greene, J.L. Johnson,E. Weimer, Phys. Fluids 14, 671 (1971).

${ }^{28}$ R.C. Grimm, J.M. Greene, and J.L. Johnson, Methods in Computational Physics, 16, 253 (1976).

${ }^{29}$ R.V. Budny, M.G. Bell, H. Biglari, M. Bitter, C.E. Bush, C.Z. Cheng, E.D. Fredrickson, B. Grek, K.W. Hill, H. Hsuan, A.C. Janos, D.L. Jassby, D.W. Johnson,L.C. Johnson, B. Leblank, D.C. McCune. D. R. Mikkelson, H.K. Park, A.T. Ramsey, S.A. Sabbagh, S.D. Scott, J.F. Schivell, J.D. Strachan, B.C. Stratton, E.J. Synakowski, G. Taylor, M.C. Zarnstorff, and S.J. Zweben, Nuclear Fusion 32, 429 (1992) 


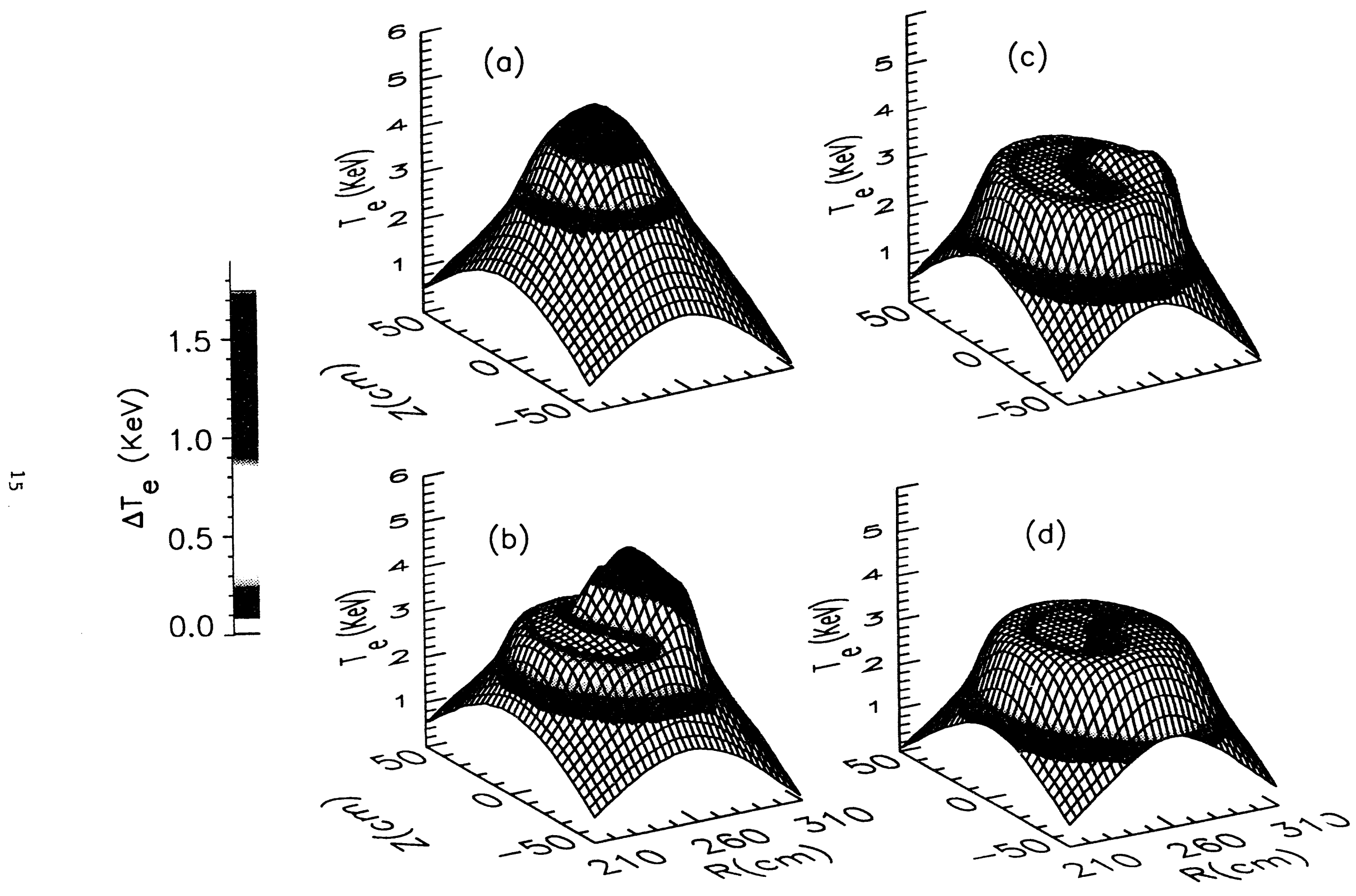



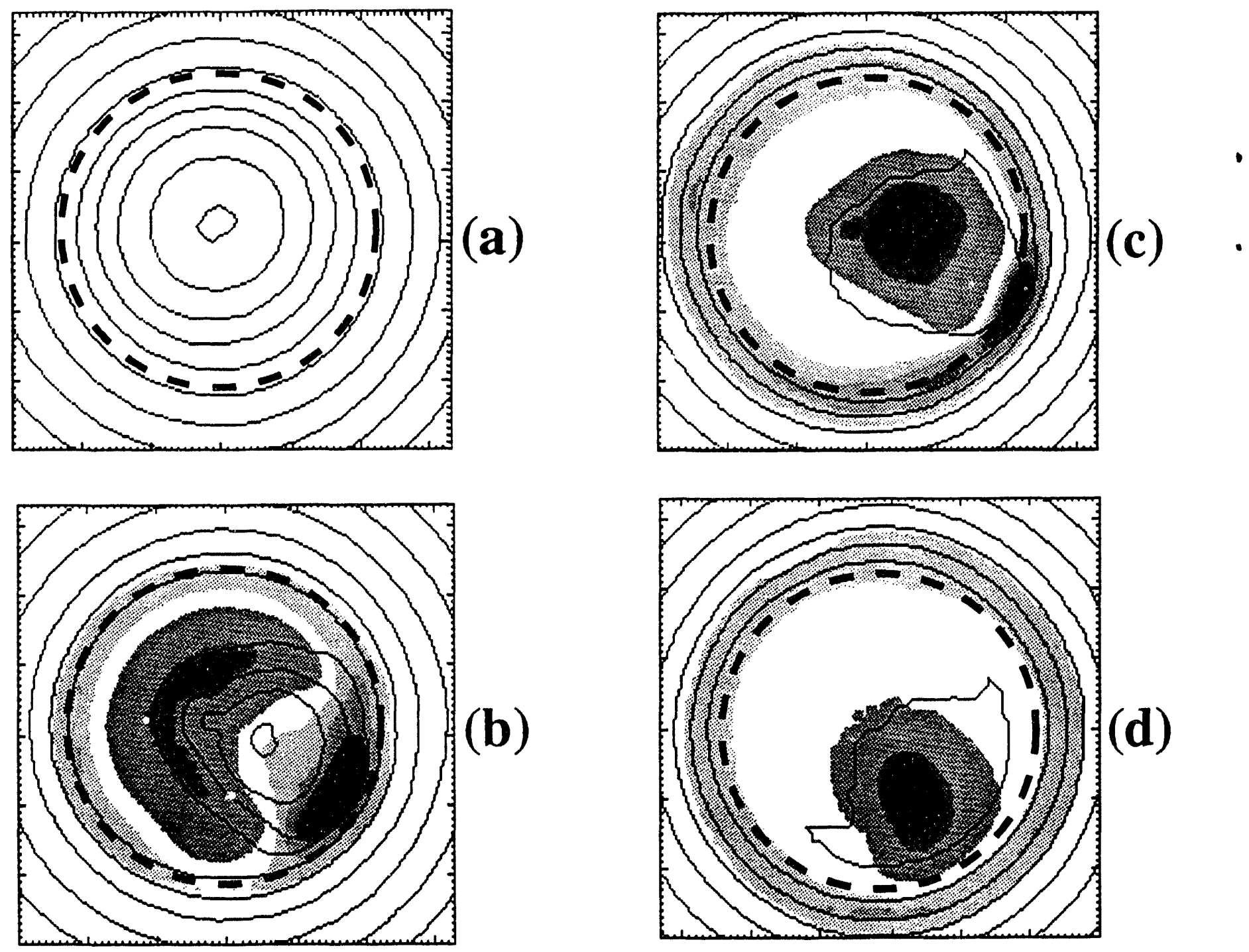

$-1 \times 10^{4} \mathrm{KeV} / \mathrm{s}$

(b)

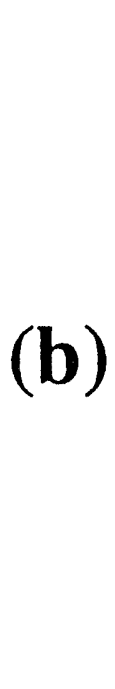

$+1 \times 10^{4} \mathrm{KeV} / \mathrm{s}$

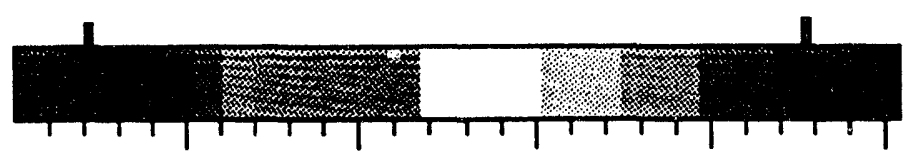

Heat

Heat

Loss

Gain

Fig. 2 

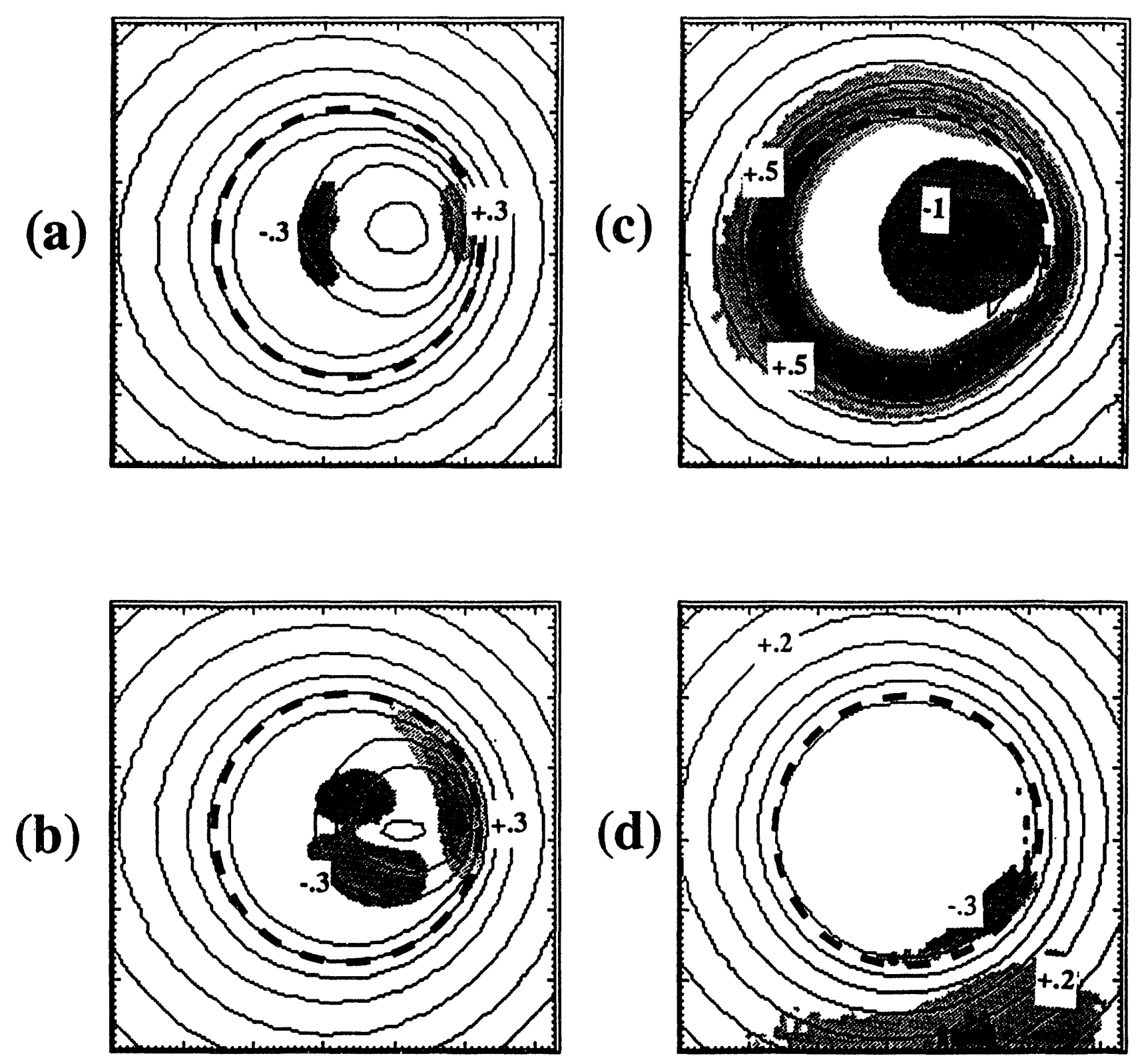

$.1 \times 10^{4} \mathrm{KeV} / \mathrm{s}$

$+1 \times 10^{4} \mathrm{KeV} / \mathrm{s}$.

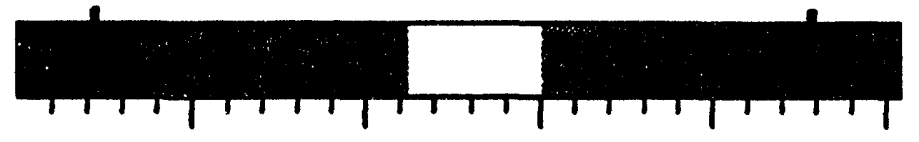

Heat

Loss

Heat

Gain

Fig. 3 


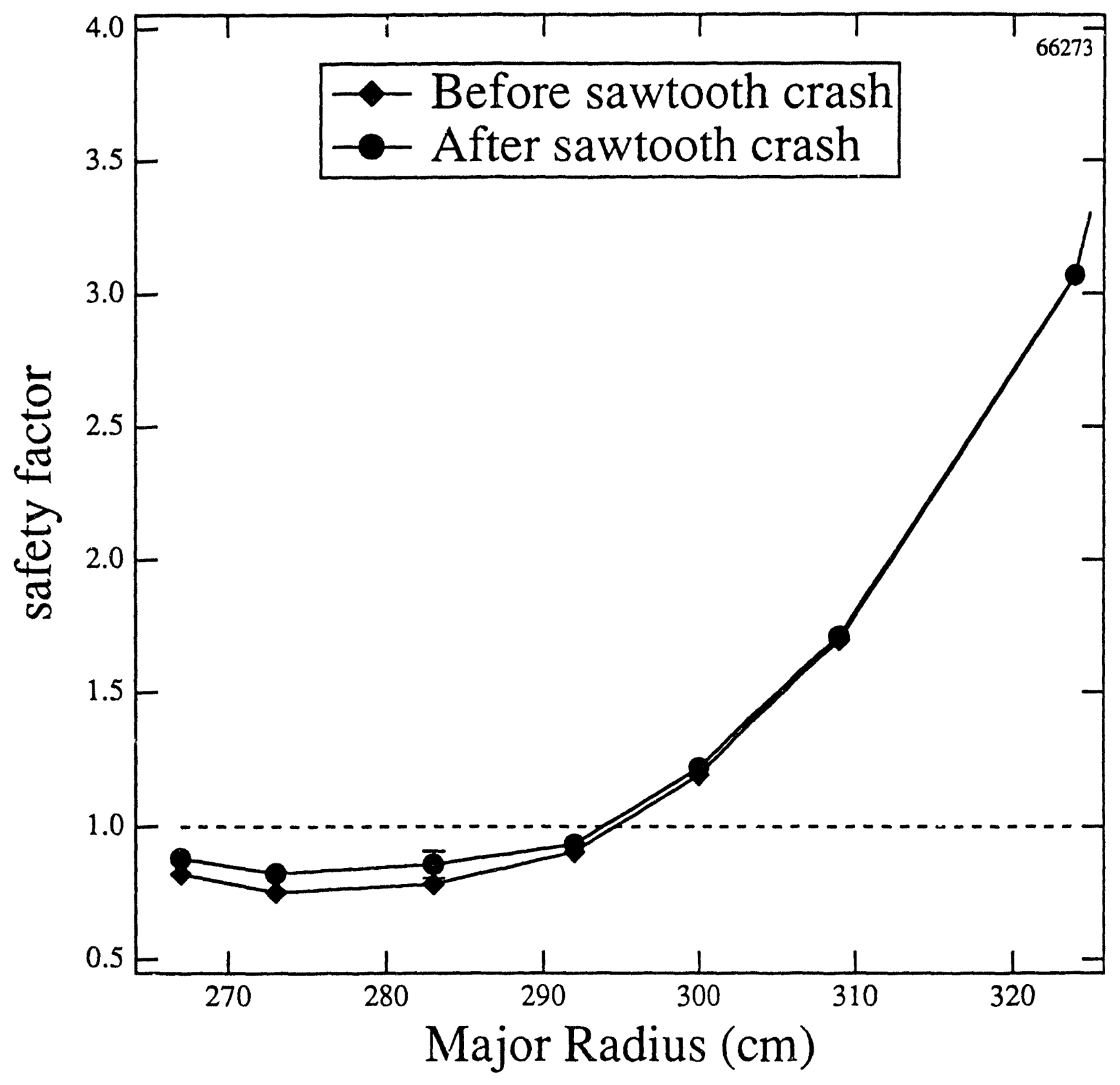

Fig. 4 

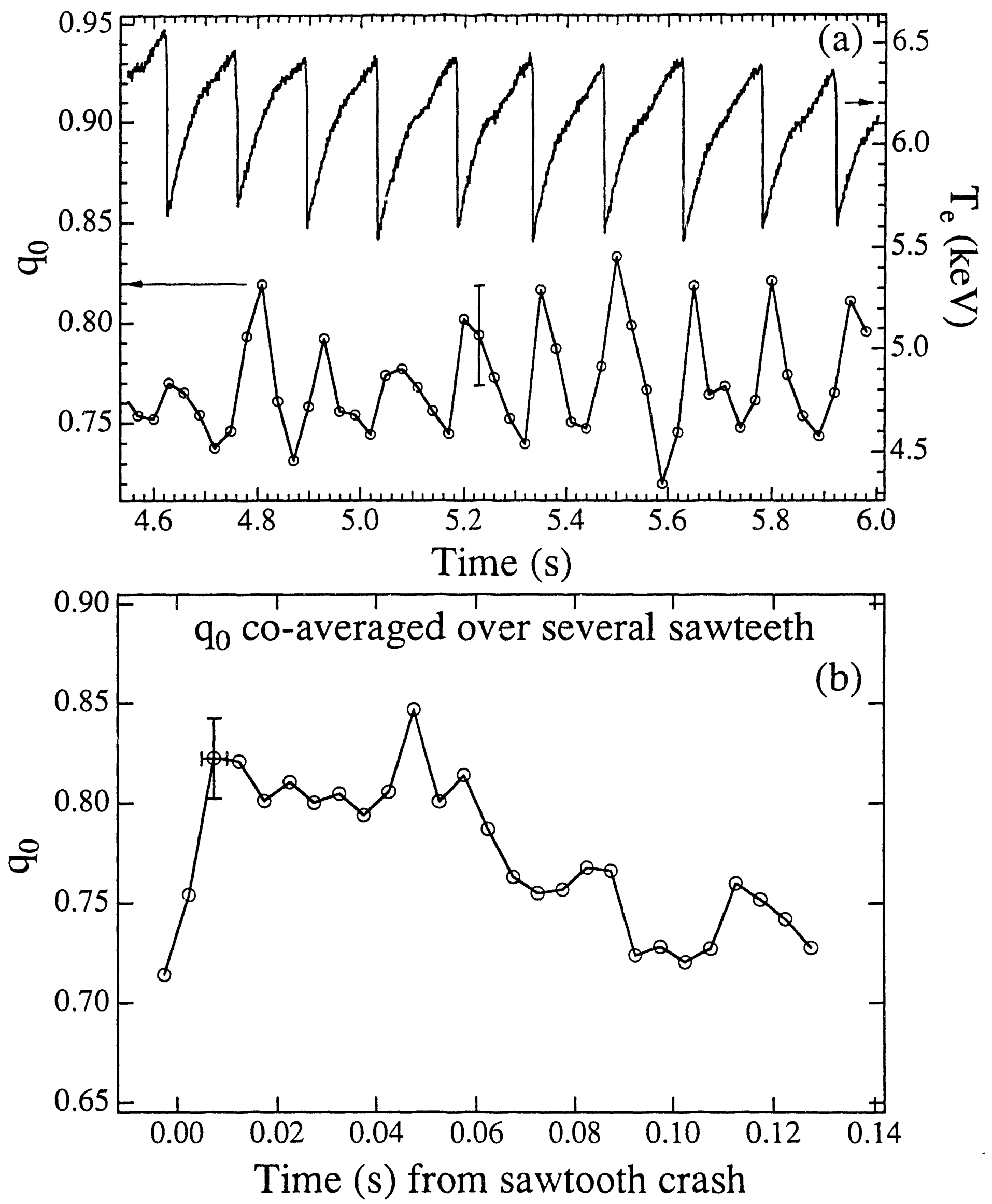

Fig. 5 


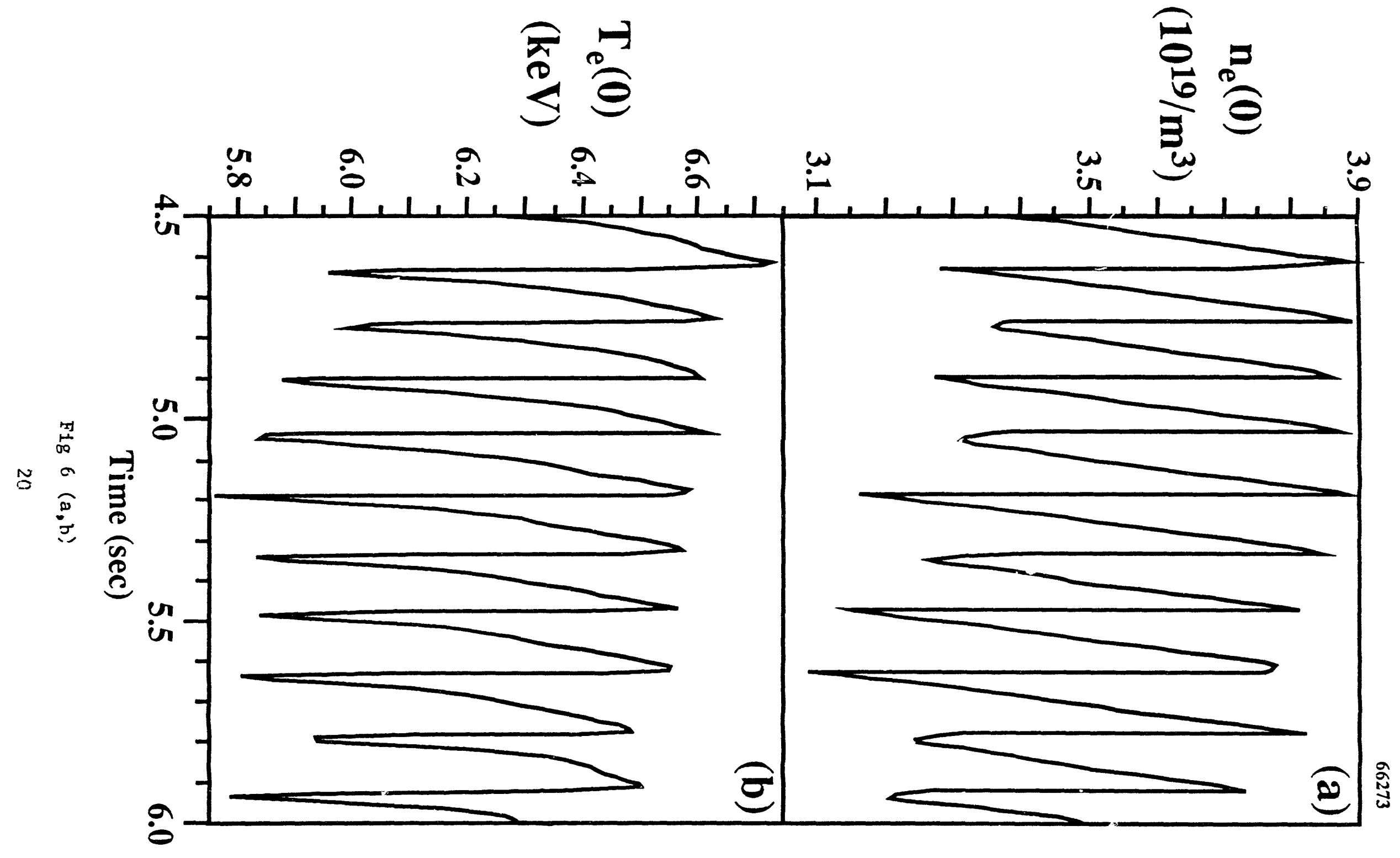




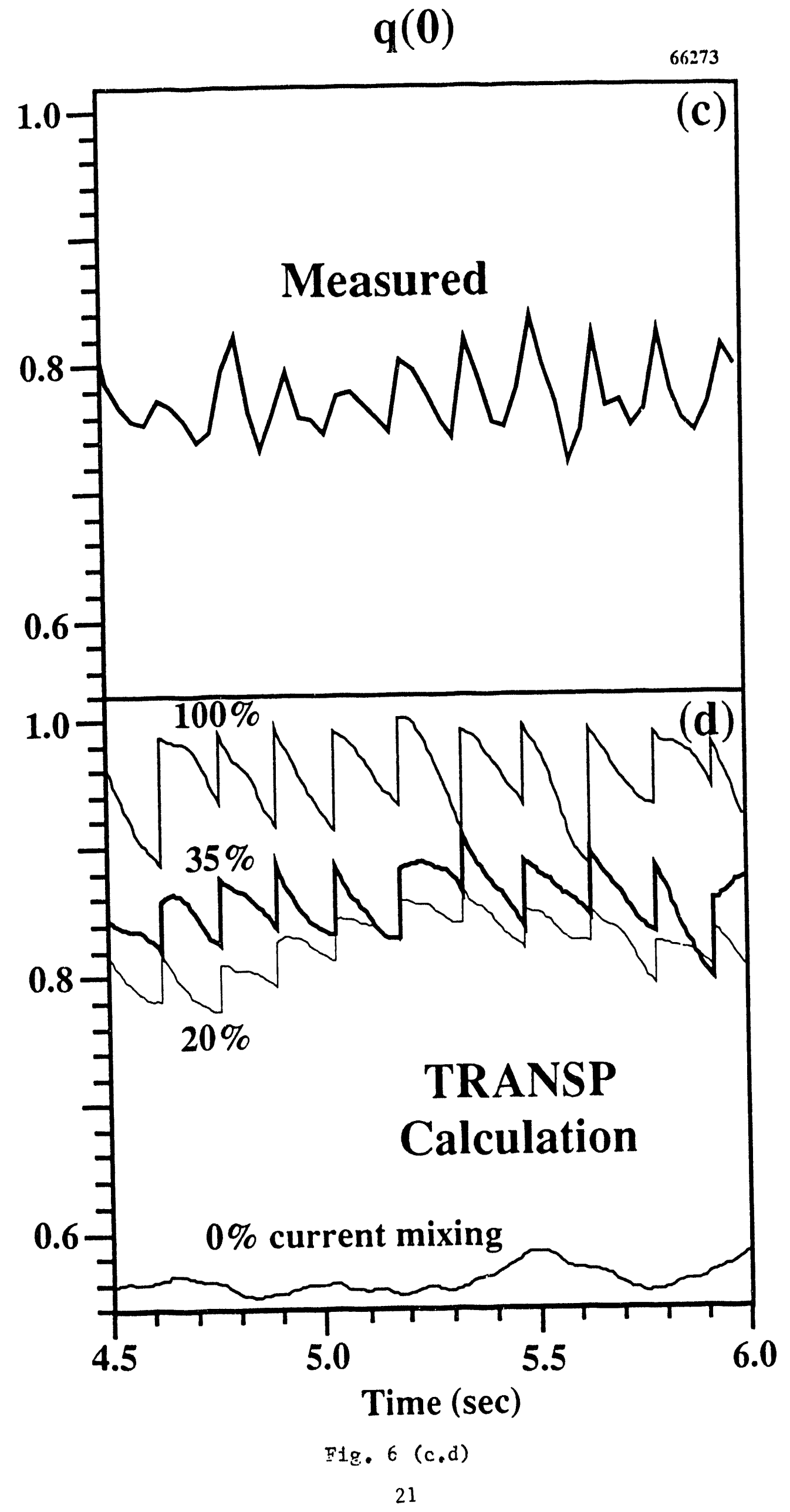


Dr. F. Paoloni, Univ, of Wollongong, AUSTRALIA

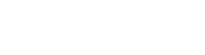

Prof. R.C. Cross, Univ. of Sydnoy, AUSTRALIA

Prof. I.R. Jones, Flinders Univ, AUSTRALIA
Plasme Rosearch Lab., Australian Nat. Univ., AUSTRALIA

Prof. F. Cap, Inst. for Theoretical Physics, AUSTRIA

Prof. M. Heindler, Institut fur Theoretische Physik, AUSTRIA

Prof. M. Goossens, Astronomisch instituUt, BELGIUM

Ecole Royalo Militaire, Lab. de Phy. Plasmas, BELGIUM

Commission-European, DG. XII-Fusion Prog., BELGIUM

Prot. R. Boucique, Aijksuniversiteit Gent, BELGIUM

Dr. P.H. Sakanaka, Instituto Fisica, BRAZIL

Prol. Dr. I.C. Nascimento, Instituto Fisica, Sao Paulo, BRAZIL Instituto Nacional De Pesquisas Espaciais-INPE, BRAZIL Documents Office, Atomic Energy of Canada Ltd., CANADA

Ms. M. Morin, CCFMTokamak de Varennes, CANADA

Dr. M.P. Bachynski, MPB Technologies, Inc., CANADA

Dr. H.M. Skarsgard, Univ. of Saskatchewan, CANADA

Prof. J. Teichmann, Univ. of Mnntreal, CANADA

Prot. S.R. Sreenivasan, Univ. of Calgary, CANADA

Prot. T.W. Johnston, INAS-Energie, CANADA

Dr. R. Bolton, Centre canadien de fusion magnétique, CANADA

Dr. C.R. James,., Univ. of Alberta, CANADA

Dr. P. Lukic, Komenského Universzita, CZECHO-SLOVAKIA

The Librarian, Culham Laboratory, ENGLAND

Library, R61, Ruthertord Appleton Laboratory, ENGLAND

Mrs. S.A. Hutchinson, JET Library, ENGLAND

Dr. S.C. Sharma, Univ. of South Pacific, FIJI ISLANDS

P. Măhơnen, Univ. of Helsinki, FINLAND

Prof. M.N. Bussac, Ecole Polytechnique, FRANCE

C. Mouttot, Lab. de Physique des Milieux lonisés, FRANCE

J. Radet, CEN/CADARACHE - Bat 506, FRANCE

Prot. E. Economou, Univ. of Crete, GREECE

Ms. C. Ainni, Univ. of loannina, GREECE

Preprint Library, Hungarian Academy of Sci., HUNGARY

Dr. B. DasGupta, Saha Inst. of Nucloar Physics, INDIA

Dr. P. Kaw, Inst. tor Plasma Research, INDIA

Dr. P. Rosenau, Israel inst. of Technology, ISRAEL

Librarian, Intomational Center for Theo Physics, ITALY

Miss C. Do Palo, Associazione EURATOM-ENEA, ITALY

Dr. G. Grosso, letituto di Fisica del Plasma, ITALY

Prot. G. Rostangni, Istituto Gas Ionizzati Dol Cnr, ITALY
Dr. H. Yamato, Toshiba Res a Devel Conter, JAPAN

Prof. I. Kawakami, Hiroshima Univ., JAPAN

Prof. K. Nishikawa, Hiroshima Univ., JAPAN

Librarian, Naka Fusion Research Establishment, JAERI, JAPAN

Director, Japan Atomic Energy Research Inst., JAPAN

Prot. S. Itoh, Kyushu Univ., JAPAN

Research Info. Cr., National Instit. for Fusion Scienco, JAPAN

Prof. S. Tanaka, Kyoto Univ., JAPAN

Library, Kyoto Univ., JAPAN

Prof. N. Inove. Univ. of Tokyo, JAPAN

Secretary, Plasma Section, Electrotechnica! Lab., JAPAN

Dr. O. Mitarai, Kumamoto Inst. of Technology, JAPAN

Dr. G.S. Lee, Korea Basic Sci. Cr., KOREA

J. Hyeon-Sook, Korea Alomic Energy Research Inst., KOREA

D.I. Choi, The Korea Adv. Inst. of Sai. \& Tech., KOREA

Prof. B.S. Liley, Univ. of Waikato, NEW ZEALAND

Inst of Physics, Chinese Acad Sci PEOPLE'S REP. OF CHINA Library, Inst. of Plasma Physics, PEOPLE'S REP. OF CHINA

Tsinghua Univ. Library, PEOPLE'S REPUBLIC OF CHINIA

Z. Li, S.W. Inst Physics, PEOPLE'S REPUBLIC OF CHINA

Prof. J.A.C. Cabral, Instituto Superior Tecnico, PORTUGAL

Prot. M.A. Hellberg, Univ. of Natal, S. AfRiCA

Prot. D.E. Kim, Pohang Inst. of Sci. \& Toch., SO. KOREA

Prot. C.I.E.M.A.T, Fusion Division Library, SPAIN

Dr. L. Stenflo, Univ. of UMEA, SWEDEN

Library, Royal inst. of Technology, SWEDEN

Prot. H. Wilhelmson, Chalmers Univ. of Tech., SWEDEN

Centre Phys. Des Plasmas, Ecole Polytech, SWITZERLAND

Bibliotheok, Inst. Voor Plasma-Fysica, THE NETHERLANDS

Asst. Prot. Dr. S. Cakir, Middle East Tech. Univ., TURKEY

Dr. V.A. Glukhikh,Sci. Res. Inst. Electrophys. I Apparatus, USSR

Dr. D.D. Ryutov, Siberian Branch of Academy of Sa., USSR

Dr. G.A. Eliseev, I.V. Kurchatov Inst., USSR

Librarian, The Ukr.SSR Academy of Sciences, USSR

Dr. L.M. Kovrizhnykh, Inst. of General Physics, USSR

Kemforschungsanlage GmbH, Zentrabibliothek, W. GERMANY

Bibliothek, Inst. For Plasmatorechung, W. GERMANY

Prot. K. Schindler, Ruhr-Universitat Bochum, W. GERMANY

Dr. F. Wagner, (ASDEX), Max-Planck-Institut, W. GERMANY

Librarian, Max-Planck-Instifut, W. GERMANY 


\section{DATE}

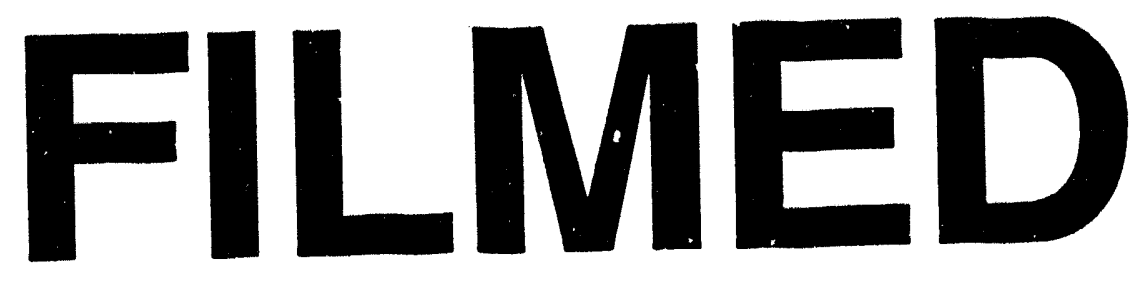

$10 / 21 / 94$
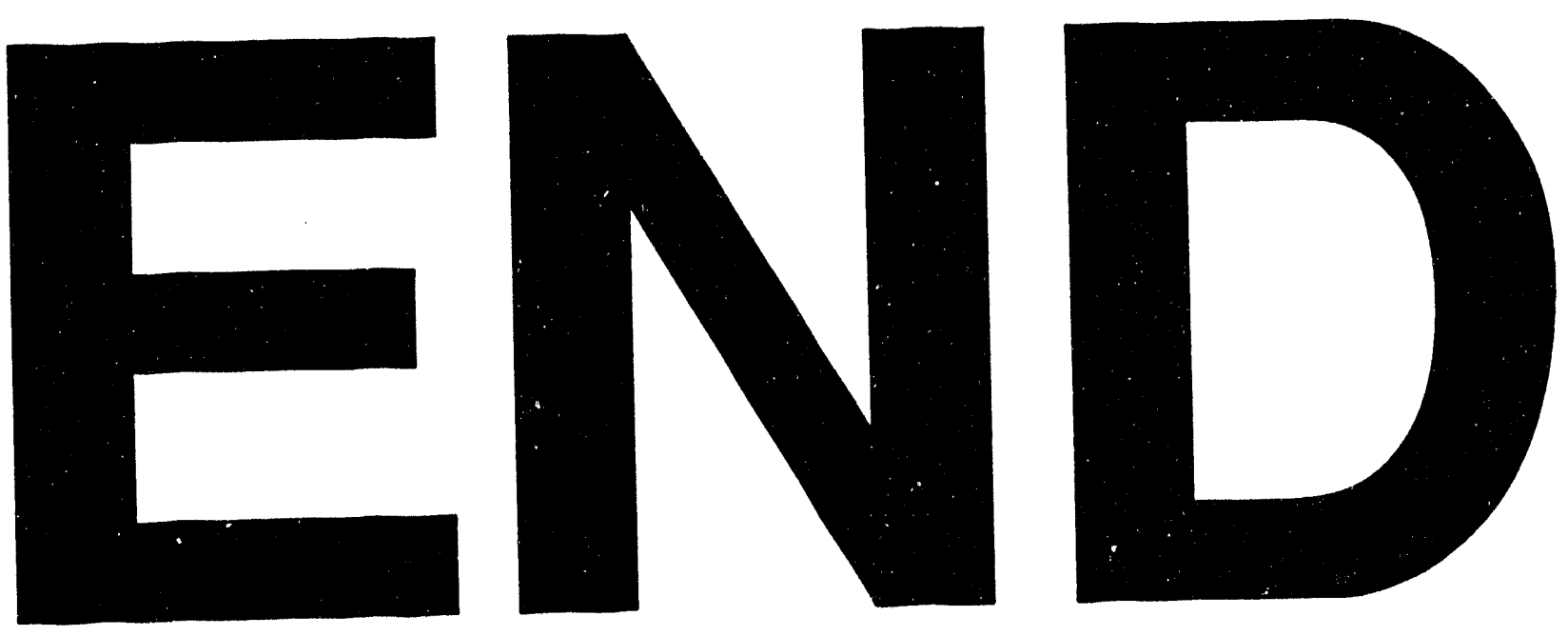


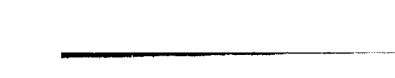

